\section{DRAFT ORAL HEALTH GUIDANCE PUBLISHED}

The National Institute for Health and Care Excellence (NICE) has published a draft guideline to help local authorities improve oral health. The draft guideline makes recommendations to help councils work with other local organisations (such as the NHS, nurseries, schools, community centres and voluntary groups) to develop a local strategy on oral health and deliver community-based activities to:

- Improve diet and reduce consumption of sugary food and drinks, alcohol and tobacco

Improve oral hygiene

- Increase the availability of fluoride (such as using fluoride toothpaste - but water fluoridation is not within the scope of this guideline)

- Increase access to dental services.

Professor Mike Kelly, Director for the Centre of Public Health at NICE, said: 'Helping local authorities to improve oral health in their communities is vital in helping people live a healthier life overall. We are keen to receive comments on this draft version of this new guideline from anyone who is likely to be involved in making key decisions in their local area. We also keen to hear from those delivering frontline services in dentistry, health, social care and education.' A copy of the draft public health guidance can be found at http://guidance.nice.org.uk/PHG/61.

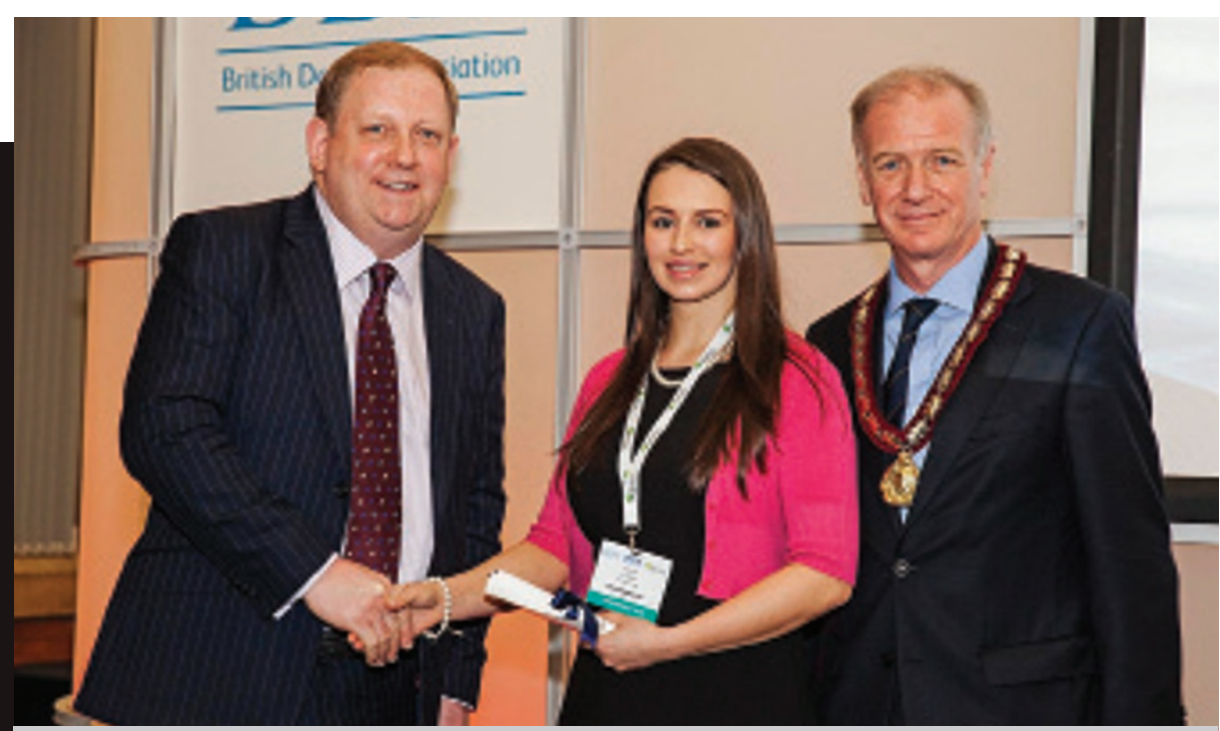

\title{
FIONA IS OUTSTANDING STUDENT OF 2013
}

Dental nurse Fiona Cullen has received the British Dental Association (BDA) Outstanding Student of 2013 award for being the student who attained the highest standing in the BDA Education Radiography examination in 2013.

Fiona was presented with her award by Peter Ward, BDA CEO, and Alasdair Miller, BDA President, at the British Dental Conference and Exhibition 2014, held in Manchester in April.

This is the first time that this award has been given. The BDA launched its own qualifications in Radiography and in Oral Health Education in 2013, building on the success of its online courses in the same disciplines, which have been offered since 2006. BDA Education has helped over 1,000 dental care professionals (DCPs) gain nationally-recognised qualifications.
Fiona, who works at Finaghy Orthodontic Practice in Belfast, qualified as a dental nurse in 2011 and is actively engaged in further education to gain new skills.

For more information on the BDA's online courses, visit www.bda.org/dcps/course/.

Look out for a full conference report in the June issue of BDJ Team.

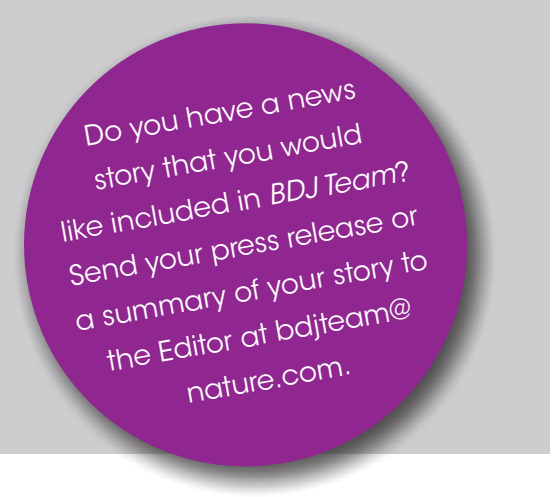

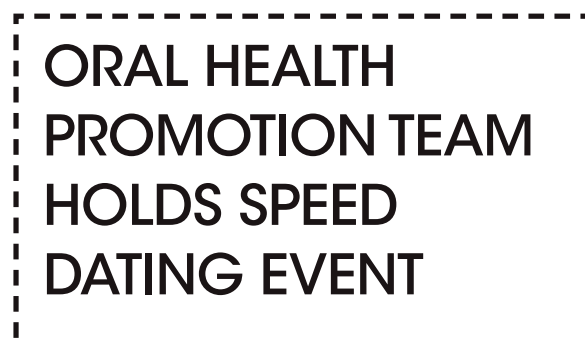

(1)

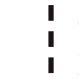

,

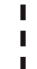

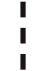

I

dental health professionals.

I Delegates from dental practices in

I Nottingham City, Nottinghamshire County

I and Bassetlaw were joined by Barry

Cockcroft, Chief Dental Officer England,

I and Sandra Whiston, Dental Public Health

Consultant for the East Midlands, who

I set the scene by presenting international,

national and local data.

The theme for the conference was

children and focussed on families

with children under five-years-old. In

I Nottingham City $39 \%$ of five year olds

had experience of dental disease (England

I average $28 \%$ ) and in the County $20 \%$ have

I had active decay. This highlighted the

I importance of this agenda in the local area

Julia Wilkinson, Head of Oral Health

I Promotion and 'Chief Tooth Fairy' said:

'Current oral health activities we are

working on in Nottingham include

The City Smiles and Incredible Mouths

programmes which involve training to

I midwifery, health visiting and school health

I teams to ensure they are all delivering up

to date key oral health messages at crucial

developmental stages. New initiatives

include a drive to increase dental access

I of families with two year olds through

I the "two year ticket scheme" with health

I visiting and dental practices.'

The event included speakers, dental reps, a raffle, goody bags, workshops and 'speed

I dating' - an opportunity for local services to liaise with dental practices for the first time.

The next conference, on older children

and young people, is planned for October. 